\title{
A Regulation Model for the Solvency of Banking System: Based on the Pinning Control Theory of Complex Network
}

\author{
Xiang Gao, Ming Zhou, and Hongbing Ouyang \\ School of Economics, Huazhong University of Science and Technology, Wuhan, Hubei 430074, China \\ Correspondence should be addressed to Hongbing Ouyang; ouyanghb@126.com
}

Received 3 May 2017; Revised 28 July 2017; Accepted 20 August 2017; Published 20 December 2017

Academic Editor: Ricardo López-Ruiz

Copyright ( 2017 Xiang Gao et al. This is an open access article distributed under the Creative Commons Attribution License, which permits unrestricted use, distribution, and reproduction in any medium, provided the original work is properly cited.

\begin{abstract}
A dynamic model is proposed based on the pinning control theory of complex network in order to simulate government bailouts against financial crisis and then is applied to a stress test of China's interbank borrowing and lending network from 2007 to 2014 . The proposed model takes many cases into account, so it is able to simulate bailout effects with different parameters, capture temporal and individual differences of banks' spillovers effects, and reflect their sensitivity to government bailouts indirectly. This paper offers an innovative model to identify the systemic-important banks in financial crisis and construct a macroprudential regulation system based on network theory.
\end{abstract}

\section{Introduction}

The characteristic of financial network is one of explanations about systemic risk and contagion. Recently, governments [1] take some measures such as macroprudential regulation to solve these problems. As a result, the macroprudential regulation framework and methodology become important subjects of researches and discussions. It was Allen and Gale [2] who first applied the network theory to study the financial system and later a lot of researchers analyzed and expanded the financial systems worldwide based on the network theory and drew different conclusions. The theory network offers a comprehensive and systematic analysis perspective and leads people to have a better understanding about the formation of systemic risks $[3,4]$ and contagion modes [5-7] as well as effective bailout measures $[8,9]$.

In general, a wealth of literature on the studies of financial system using the network theory is concentrated on the description of financial systems. Huang and Jia [10] validated the network model using the data of large value payment system, described China's bank network from multiple dimensions, and found important bank nodes. With Australia's interbank market data, Sokolov et al. [11] constructed the interbank network and studied its topological properties. Drehmann and Tarashev [12] measured the systemic importance of interrelated banks. Some other literature mainly discusses the modeling methods. Mistrulli [13], Degryse and Nguyen [14], and Ma et al. [15] applied the maximum entropy method to study the structure of bank networks in different countries. However, Mistrulli [13] found that the risk contagion effect was underestimated in the bank networks constructed with the maximum entropy method and thus added a constraint totally with the actual situation. Later, Wang et al. [16] built the interbank market network based on a constraint of interbank borrowing and lending preference and measured the systemic risks. Anand et al. [17] combined the minimum density solution and the maximum entropy method to determine the boundary of contagion effect. Above all, most literature just takes advantage of the network theory to study the macroscopic characteristics of bank system, identify important banks, or measure the factors of systemic risks [18-20] but hardly involves the controllability of network.

It is obvious that we could understand financial system more clearly and deeply after studying the controllability of financial network and thus provide some bailouts strategies and supervision model accordingly. In this paper, we pay more attention to the optimization of policy and supervision; for more details, we present a model on bailouts for the solvency of banking system based on the pinning control 
theory of complex network [21-25] and then apply it to a stress test of China's interbank network, which generates a methodology about financial regulation.

The pinning control theory mentioned above has been used to study network synchronization thoroughly and also widely applied to opinion evolution of social network, multimode laser system, and so on $[26,27]$. The basic thinking of pinning control is to selectively exert control on a few nodes in the network so that the whole network shows desired behaviors [28]. Rong et al. [29] and Tang et al. [30] compared selective strategies of pinning control. Besides, Turci and Macau [31] found that a max-degree pinning scheme is better than a random pinning one in a disassortative network. Moreover, Zou and Chen [32] illustrated that pinning the big nodes is, in fact, always better than pinning the small ones in normalized weighted scale-free networks. This paper extends pinning control to financial network and deems the government's bailout against risks as pinning control or an exogenous policy restraint for certain banks, so that the solvency of the whole bank network changes in line with the government's expectations and then the goal of bailout is attained. The comparative result of different bailout strategies offers a basis of judgment for bailout behaviors [33].

The rest of this paper is organized as follows. Section 2 constructs a model of financial network based on interbank borrowing and lending and further builds the dynamic evolution model of solvency based on the pinning control theory of complex network; Section 3 analyzes China's bank system using the aforementioned model, compares the results of government bailouts in different cases, and gives suggestions for policy-making; Section 4 summarizes the whole paper, discusses the significance of the dynamic evolution model of solvency in macroprudential regulation as well as its role in the process of government's decision-making as a new dynamic stress test method.

\section{Modeling}

2.1. Financial Network Model Based on Interbank Borrowing and Lending. Since it is difficult to obtain complete information of both parties in interbank borrowing and lending, the maximum entropy method [34] is adopted to estimate the structure of interbank borrowing and lending in China and establish a directed network composed of nodes showing one-to-one correspondence with banks and weighted edges ${ }^{1}$ according to the common practice in studies on bank systems.

To compare the interrelation degrees revealed in interbank borrowing and lending in the same dimension, the concrete numerical values are subject to normalization to obtain a relative weight matrix $M_{t}$. As the network changes with time, there is a relative weight matrix at any time $t$, which is given by

$$
M_{t}=\left[\begin{array}{ccc}
M_{11} & \cdots & M_{1 N} \\
\vdots & \ddots & \vdots \\
M_{N 1} & \cdots & M_{N N}
\end{array}\right]
$$

in which the weight of edge connecting nodes such as $X_{i j}$ represents the percentage of the lending amount from bank $i$ to bank $j$ in the total lending amount of bank $i$ at time $t$ and the diagonal element is zero because the borrowing and lending amount of a bank to itself are zero.

$$
X_{i i}=0 \text {. }
$$

Then, $M_{t}$ turns to $X_{t}$ :

$$
X_{t}=\left[\begin{array}{ccc}
X_{11} & \cdots & X_{1 N} \\
\vdots & \ddots & \vdots \\
X_{N 1} & \cdots & X_{N N}
\end{array}\right]
$$

The elements $X_{i j}$ in $X_{t}$ can be solved by

$$
\begin{aligned}
X_{i j} & =\min \sum_{i=1}^{N} \sum_{j=1}^{N} X_{i j} \ln \left(\frac{X_{i j}}{X_{i j}^{o}}\right), \\
h_{i} & =\sum_{j=1}^{N} X_{i j}, \\
v_{j} & =\min \sum_{i=1}^{N} X_{i j} .
\end{aligned}
$$

And if $i \neq j, X_{i j}^{o}=h_{i} * v_{j}$; if $i=j, X_{i j}^{o}=0, X_{i j}=0$, and $0 \ln (0 / 0)=0$, which are the constraint conditions.

Therefore, a larger weight of edge connecting bank $i$ and bank $j\left(X_{i j}\right)$ indicates that bank $i$ has a closer relation with bank $j$ and simultaneously reflects the relative importance of bank $j$ among all banks holding a lending relation with bank $i$. Similarly, $X_{j i}$ represents the relative importance of bank $j$ according to borrowing relation. Based on such a directed network of weighted edges, an evolution model of solvency which is affected by the interrelation among banks is constructed to study the bailouts of the lender of last resort against systemic risk.

\subsection{Dynamic Evolution Model of Solvency Based on Pinning} Control. The bailouts of "the lender of last resort" to certain banks in the bank system can be interpreted as the pinning control on the solvency of individuals in the network which enables the individuals to reach the desired values first and then brings the whole network to a normal level. In complex financial network, it will be a highly efficient and cost-saving method to maintain the stability of the whole financial system by exerting control on a few key financial institutions, and in particular, prompt government bailouts can stimulate the recovery of economic vigor when the systemic risk occurs to the financial system. This paper develop an dynamic evolution model, which takes solvency as a basic parameter, banks are mutually affected in terms of solvency due to their interrelation, government bailouts are deemed as exogenous control on the network and brought into the influential factors for solvency to judge bank differences and bailouts effect through differential treatment, and also the result clarifies how to identify "important financial institutions." 


\subsubsection{Hypotheses}

Hypothesis 1. There are $N$ participants endowed with solvency in a system $\left(\right.$ solvency $\left._{i}(t) \in(0,1)\right)$. 0 suggests that a bank suffers from serious solvency crisis and faces with bankruptcy; 1 indicates that a bank is in the state of normal operation and shows high solvency.

Hypothesis 2. When an adverse exogenous shock acts on bank system, all will suffer from solvency crisis, and the solvency of each node in the network deviates from its nominal value and fluctuates in the range of small value. Considering that the initial value of solvency does not affect the stability of network ${ }^{2}$, the initial values of solvency of $N$ banks are taken from the range of $[0.2,0.4]$ randomly and satisfy the requirement of uniform distribution. The central bank, as "the lender of last resort," duly and moderately injects liquidity into banks so that the whole market receives bailouts and remains stable at a high level (economic revitalization) which is taken as the desired value (Aim = 1) for model. Figures 1(a), 1(b), 1(c), and 1(d) display random distribution of banks in the range of $[0.2,0.4]$, and the conclusions in this paper are verified by these different random distribution of initial solvency. And the final solvency is shown in Figure 1(e), and it is reasonable and factual that some banks' solvency is close to the standard but not up to it.

Hypothesis 3. The banks are mutually affected in terms of solvency due to their interrelation and the effects are positively correlated to the interrelation degree; that is,

$$
\text { solvency }_{i}(t+1) \propto \sum \frac{X_{i j}+X_{j i}}{\sum_{j}^{m}\left(X_{i j}+X_{j i}\right)} \text { solvency }_{j}(t) \text {. }
$$

$\sum\left(\left(X_{i j}+X_{j i}\right) / \sum_{j}^{m}\left(X_{i j}+X_{j i}\right)\right)$ represents the percentage of the borrowing and lending amount from bank $i$ to bank $j$ in the total borrowing and lending amount of bank $i$ at time $t$. There may be three relations between bank $i$ and bank $j$ : lending, borrowing, both lending, and borrowing. This paper builds the bank network based on the interbank lending and borrowing amount.

In general, the perceived solvency of a certain bank is influenced by another bank which has the debtor-creditor relationship from each other; in terms of relationship strength, it is true that the interrelation between two banks is closer when they have the bilateral relation (both debtor and creditor to each other) than when they have the only relation (either debtor or creditor). Obviously, the influence of a debtor bank on a creditor is not equivalent to a creditor's on a debtor, but we can not calculate accurately due to the complex situation in the real market. Therefore, we make a reasonable simplifying assumption that the influence on a bank will be greater when there is the bilateral relation between them, and the strength of influence depends on the sum account.

2.2.2. Dynamic Evolution Model of Solvency Based on Pinning Control. According to the evolution model of solvency, all banks suffer from financial crisis due to exogenous shocks and the government exerts pinning control on some banks selectively and changes their solvency and in turn the solvency changes are transmitted to other banks through network contagion effect so that all banks reach the desired values in the end.

The evolution model of solvency is composed of two parts. The solvency of a bank which is exempt from pinning control is affected by the solvency at the previous time node as well as the solvency of other interrelated banks, as is shown in

$$
\begin{aligned}
& \text { solvency }_{i}(t+1) \\
& =(1-\text { Inf }) \text { solvency }_{i}(t) \\
& \quad+\operatorname{Inf} \sum \frac{X_{i j}+X_{j i}}{\sum_{j}^{m}\left(X_{i j}+X_{j i}\right)} \text { solvency }_{j}(t) .
\end{aligned}
$$

It is noteworthy that some deficient banks would bid up rates on overnight loans so that crisis condition might provoke a contraction of supply, in which banks with excess liquidity charge more for overnight loans and may refuse credit altogether to banks expected to be at risk of default. Therefore, this "supply effect" might have the potential to remove all liquidity from the system and finally banks would fail. To catch this phenomenon, we set a parameter in (7) called "SC" to reflect the contraction of supply due to crisis. Equation (7) indicates the evolution law without intervention when the crisis happens. In this situation, banks' solvency will decline because of supply contraction and high credit default risk.

$$
\begin{aligned}
& \text { solvency }_{i}(t+1) \\
& =(1-\text { Inf }- \text { SC }) \text { solvency }_{i}(t) \\
& \quad+(\text { Inf }- \text { SC }) \sum \frac{X_{i j}+X_{j i}}{\sum_{j}^{m}\left(X_{i j}+X_{j i}\right)} \text { solvency }_{j}(t) .
\end{aligned}
$$

Moreover, this paper is aimed at studying the pinning control of complex financial network, so the government's exogenous constraints imposed on certain banks are considered in order to pin down the development direction of the whole network's solvency, as shown in

$$
\begin{aligned}
& \text { solvency }_{i}(t+1) \\
& =(1-\text { Inf }) \text { solvency }_{i}(t) \\
& \quad+\operatorname{Inf} \sum \frac{X_{i j}+X_{j i}}{\sum_{j}^{m}\left(X_{i j}+X_{j i}\right)} \text { solvency }_{j}(t) \\
& \quad-\operatorname{Ctrl}\left[\text { solvency }_{i}(t)-\operatorname{Aim}\right] .
\end{aligned}
$$

Banks are iterated according to different solvency evolution laws until all banks converge to the desired values. The thinking of pinning control is manifested in the government's exogenous control for banks and is shown as Ctrl[Liquity $(t)-$ Aim] in the model. Figures 2(a), 2(b), 2(c), and 2(d) display the four processes (no intervention in normal circumstances (a); crisis happens (b); no intervention when liquidity 


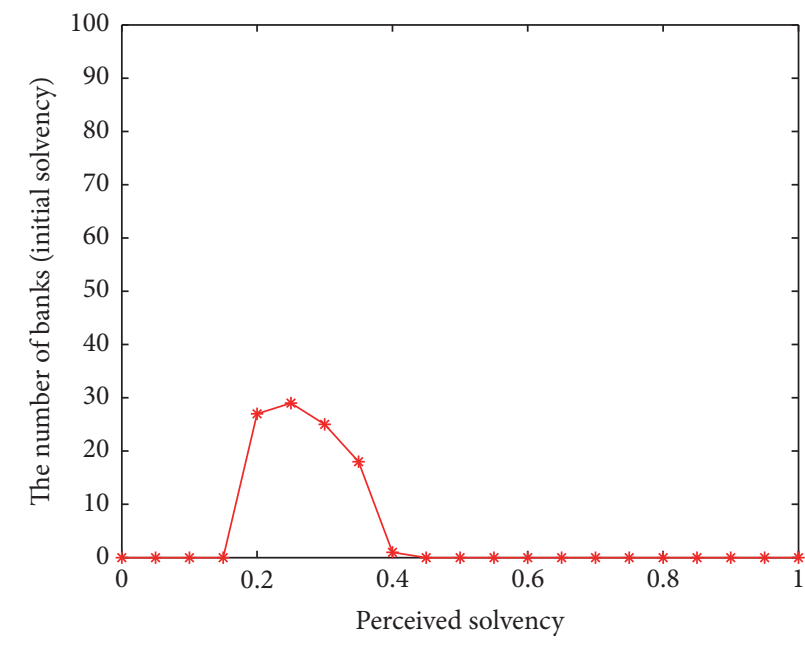

(a)

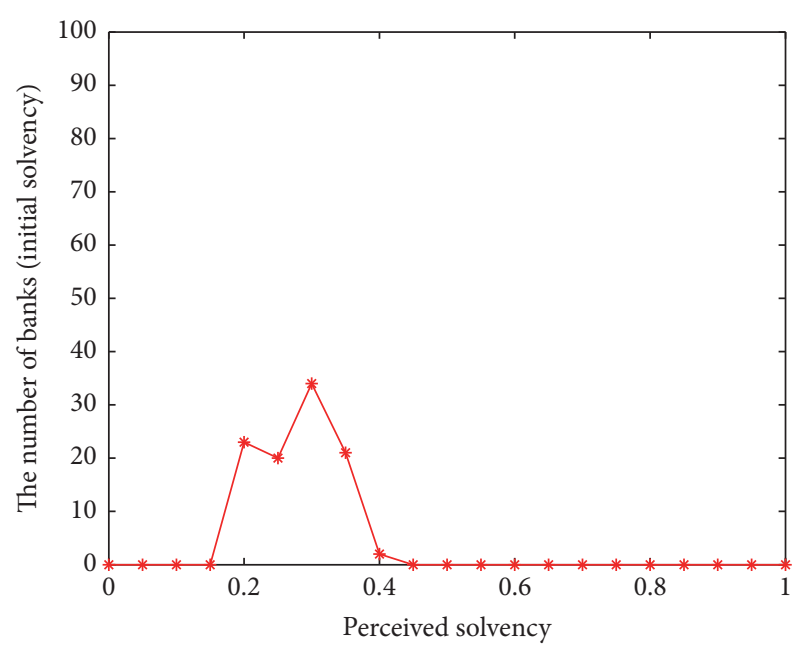

(c)

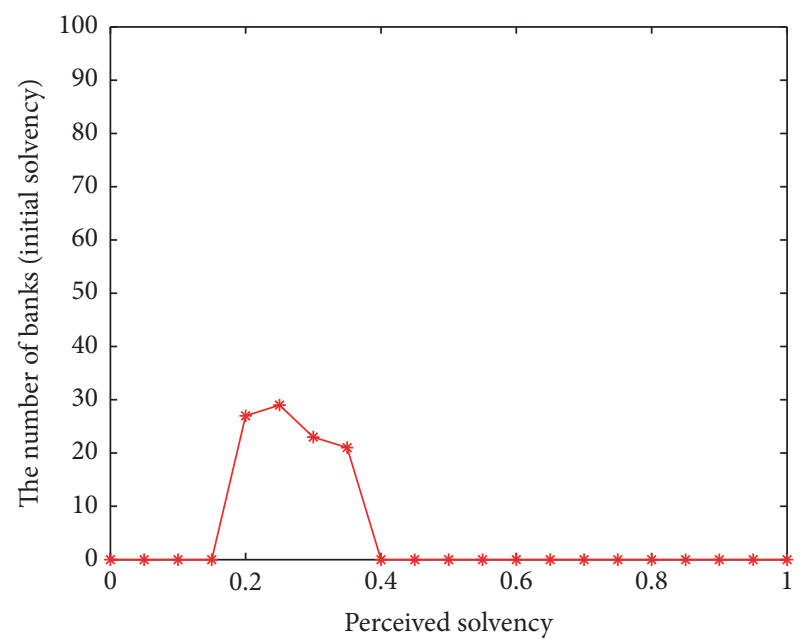

(b)

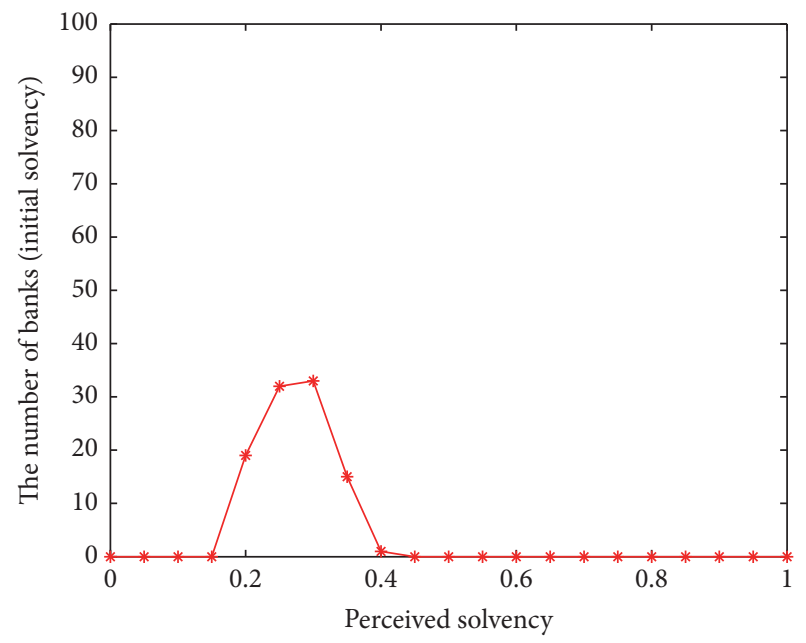

(d)

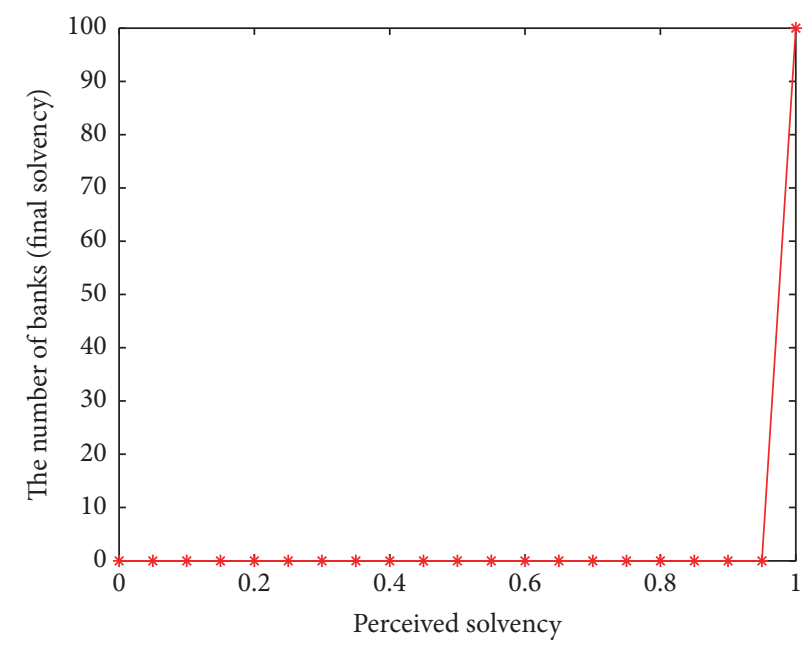

(e)

FIGURE 1: Different random distribution of banks. 


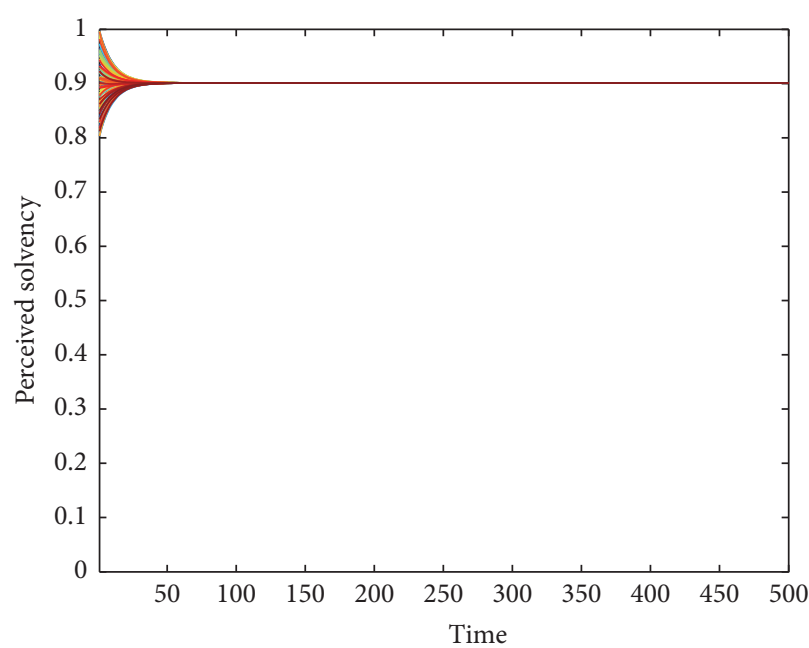

(a)

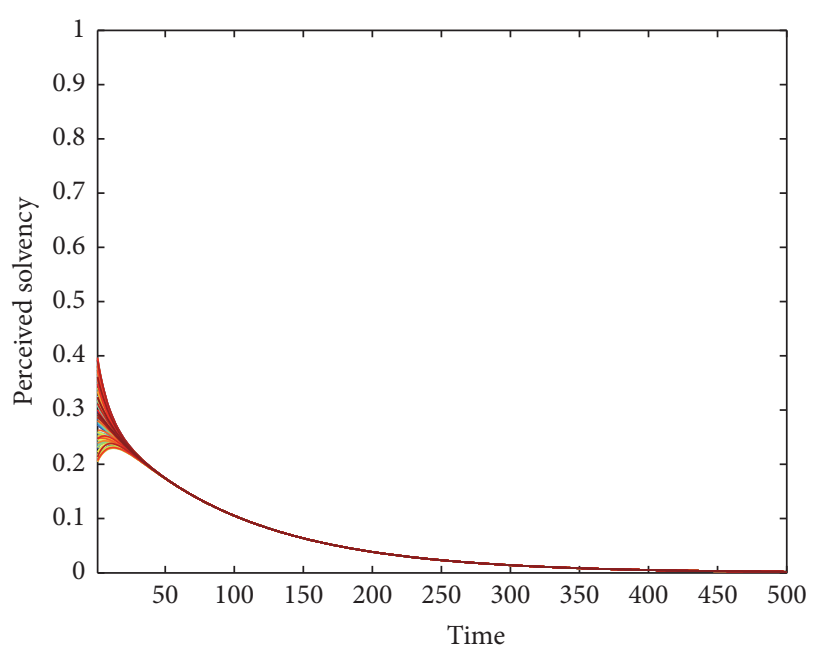

(c)

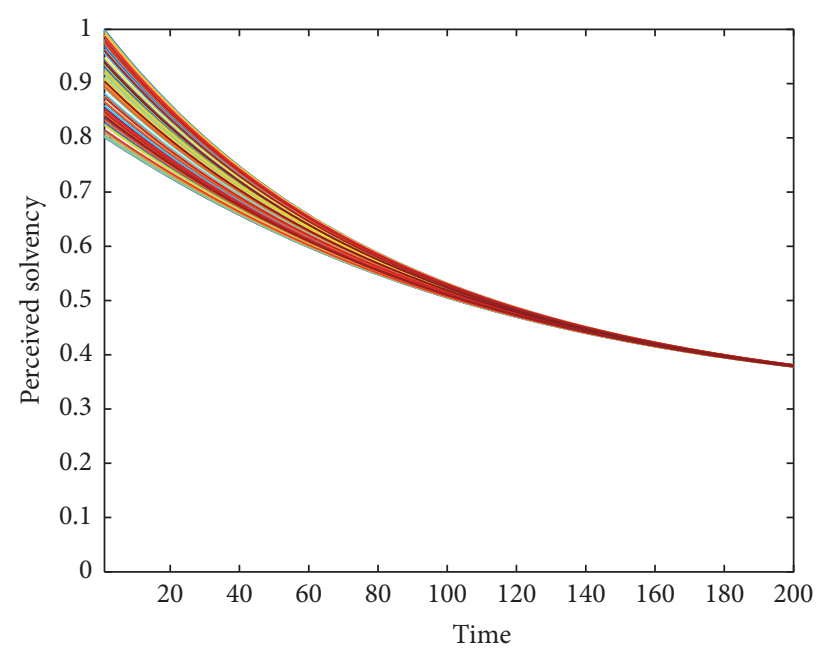

(b)

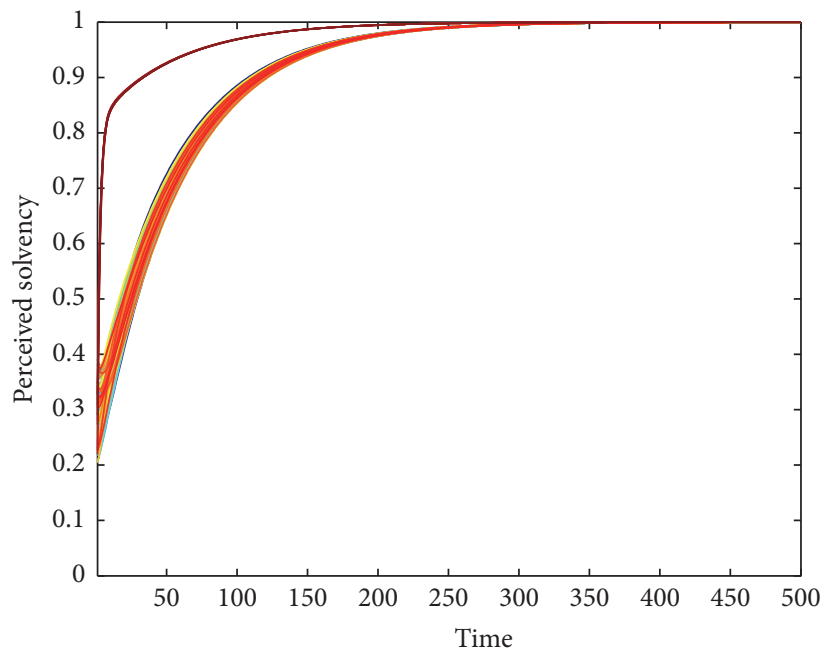

(d)

FIGURE 2: Four convergent processes ((a) presents the process without intervention in normal circumstances; (b) displays crisis extending; (c) shows no intervention when liquidity declines; (c) indicates bailouts in crisis).

declines (c); and bailouts in crisis (d)). Figure 2(c) shows that "supply effect" would reduce all banks' solvency and cause the system to collapse if there is no intervention when liquidity declines. With the comparison between (c) and (d), we can clearly catch the effectiveness of government intervention. The process with intervention is simulated to investigate the effect of variables on bailouts' result. Notation section lists main parameters in the dynamic evolution model of solvency.

(a) Network Contagion Effect (Inf). The network contagion effect suggests that the solvency of a certain bank is affected by that of interrelated banks in a given financial network. The magnitude of Inf reflects the general change of bank's solvency caused by other interrelated banks' solvency. For example, there are $n$ banks interrelated with bank $i$, so the solvency of bank $i$ is affected by these $n$ banks to different extents according to their interrelations which are the elements of matrix At. Inf is more like an multiplier with the basis of the given interrelation of banks. So it reflects the effects of some common factors which are independent of the financial network. And Inf $\in(0,1)$.

The solvency of a bank is not only subject to external disturbances but also affected by itself, so 1-Inf represents an autocorrelation coefficient. For example, Inf $=0.3$ means that the solvency of a bank is decided by the interrelated banks for $30 \%$ and itself for $70 \%$. Inf is strictly exogenous of the financial network, which depends on specific social and economic background, fluctuations of asset prices in the capital market as well as the government's macroeconomic policies, and so on. In the same network structure, the solvency of a bank at $t_{2}$ will be affected more deeply by external disturbances than at $t_{1}$ if $\operatorname{Inf}\left(t_{1}\right)<\operatorname{Inf}\left(t_{2}\right)$. Inf is an indicator on the network level, which reflects the macroscopic characteristics of bank system, and the value is of important significance to study the properties of different topological networks on the macroscopic level. 
(b) Government Control Strength (Ctrl). The extra effects on a bank by government bailouts per unit of time are defined as government control strength (Ctrl). The solvency of banks which is under control reaches the desired values gradually and Ctrl reflects the controlling force of the government's or the central bank's bailouts. Larger value of Ctrl shows a stronger government's pinning control on the solvency of banks. Ctrl is also an exogenous parameter, which is independent of the financial network and is related to the government's authority and regulatory capacity for banks and so on. Ctrl is taken as a variable in stress test, which manifests the core of pinning control, and $\operatorname{Ctrl} \in(0,1)$.

(c) Spillover Effects ( $\operatorname{Inf}_{\text {th }}$ and $\left.C t r l_{t h}\right)$. Supposing the central bank would like to inject capital into the whole bank system through certain banks, the results may vary with the time of capital injection and the selection of banks because the interrelation among banks and the roles of banks which receive bailouts change constantly in the bank system, so it reflects the differences of controlled banks in spillover effects to the whole system after bailouts. To analyze the spillover effects of different banks on the financial network, two parameters, that is, $\mathrm{Inf}_{\text {th }}$ and $\mathrm{Ctrl}_{\mathrm{th}}$, are designed.

For a given network At, $T_{\text {crit }}$ stands for the iteration time when all banks reach the desired values, and $\mathrm{Inf}_{\text {th }}$ and $\mathrm{Ctrl}_{\mathrm{th}}$ represent the minimum contagion effect and the government's minimum control strength which result in $T_{\text {crit }}$ just below a given specific indicator.

For a given $\mathrm{Ctrl}^{3}, \mathrm{Inf}_{\text {th }}$ needs to meet

$$
\begin{array}{r}
T\left(\operatorname{Inf}_{\text {th }}\right) \leq T_{\text {crit }}, \\
T\left(\text { Inf }_{\text {th }}-0.01\right)>T_{\text {crit }} .
\end{array}
$$

For a given Inf, $\mathrm{Ctrl}_{\mathrm{th}}$ needs to meet

$$
\begin{aligned}
T\left(\mathrm{Ctrl}_{\text {th }}\right) & \leq T_{\text {crit }}, \\
T\left(\mathrm{Ctrl}_{\text {th }}-0.01\right) & >T_{\text {crit }} .
\end{aligned}
$$

\section{Model Application and Analysis}

3.1. Different Financial Network. The data comes from 2007-2014 annual reports released by different banks, including 5 state-owned commercial banks, 12 joint-stock banks, and several city commercial banks. The urban credit cooperatives, rural credit cooperatives, postal saving institutions, and a few city banks are excluded because their trading volumes are small and data collection is difficult. In addition, for some banks, the default values are derived based on the averages of historical trading data. In data processing, the lending amount of a bank is the sum of amounts due from banks and loans to other banks, while the borrowing amount is the sum of deposits from other banks and loans from other banks. The relative weight matrix of eight years is obtained through computation of adjusted data. Considering that the data disclosed in early years is incomplete, so the amount of matrix elements is $71 \times 71$ in 2007, $98 \times 98$ in 2008, and $100 \times 100$ in 2009-2014, respectively ${ }^{4}$.

Since it is impossible to include all bank network data in a figure, the visual description for the distribution of 16 listed banks which account for an overwhelming percentage of the bank system is presented, which portrays the interrelation among banks intuitively. Figures 3 (a) and 3(b) ${ }^{5}$ show the distributions of 16 listed banks in the network in 2008 and 2013, respectively, in which the element size stands for the relative interbank lending and borrowing size of listed banks and the line thickness denotes the interrelation of banks (namely, the percentage of borrowing and lend amount in the total borrowing and lending amount). In 2008, the interrelations among 5 state-owned banks were strong, while the interrelations among the remaining 11 small banks were weak. However, in 2013, the interbank lending and borrowing sizes among the remaining 11 listed banks were apparently enlarged and important interrelations were established among 16 banks, suggesting the systemic importance of joint-stock banks and city commercial banks were greatly improved. The following analysis of bailouts and dynamic stress test is based on network of all banks.

3.2. The Impact of Main Parameters. In the dynamic evolution model of solvency, there are two important parameters; that is, network contagion effect, government control strength, and the network structure determine the evolution direction of solvency among banks, and critical time (the iteration time when all banks reach desired values) serves as the basis for judgment of bailouts with given network parameters. This paper is aimed at investigating the relations among three parameters when different types of banks are under pinning control in a given network and takes the analysis as a stress test method which reflects the adjustment of whole bank system's solvency resulting from bailouts to certain banks under different parameter settings.

Figure $4^{6}$ presents the relations among three parameters, namely, Inf, Ctrl, and $T_{\text {crit }}$, in the bank network in 2008 and 2013, respectively, using 3D surface. It can be found that network contagion effect (Inf) and government control strength (Ctrl) play important roles in controllability of network and the critical time varies with the pinning control on different types of banks.

When the pinning control is imposed on the relatively small city commercial banks, a plane with a threshold of $T_{\text {crit }}$ $=300$ can be observed no matter how Inf and Ctrl change, which implies that small banks are less important in the bank system and the bailouts to these banks have weak effects on the recovery of the network. When the subjects of bailouts are large banks such as joint-stock banks or state-owned banks, $T_{\text {crit }}$ is more sensitive to the changes of Inf and Ctrl. Taking 5 state-owned banks, for example, Figures 4(c) and 4(f) show that $T_{\text {crit }}$ is constantly decreased along with the increase of Inf and Ctrl, which indicates that the bailouts to large banks generate more significant results. Thus, it can be inferred that large banks usually play "leading" roles and the bailouts to large banks are highly effective in a given bank network with proper Inf and Ctrl.

In a comparison between Figures 4(a), 4(b), and 4(c) and $4(\mathrm{~d}), 4(\mathrm{e})$, and 4(f) respectively, it seems that critical time and bank size are negatively correlated to some extent when Inf and Ctrl are given, that is to say, bailout to larger banks may 


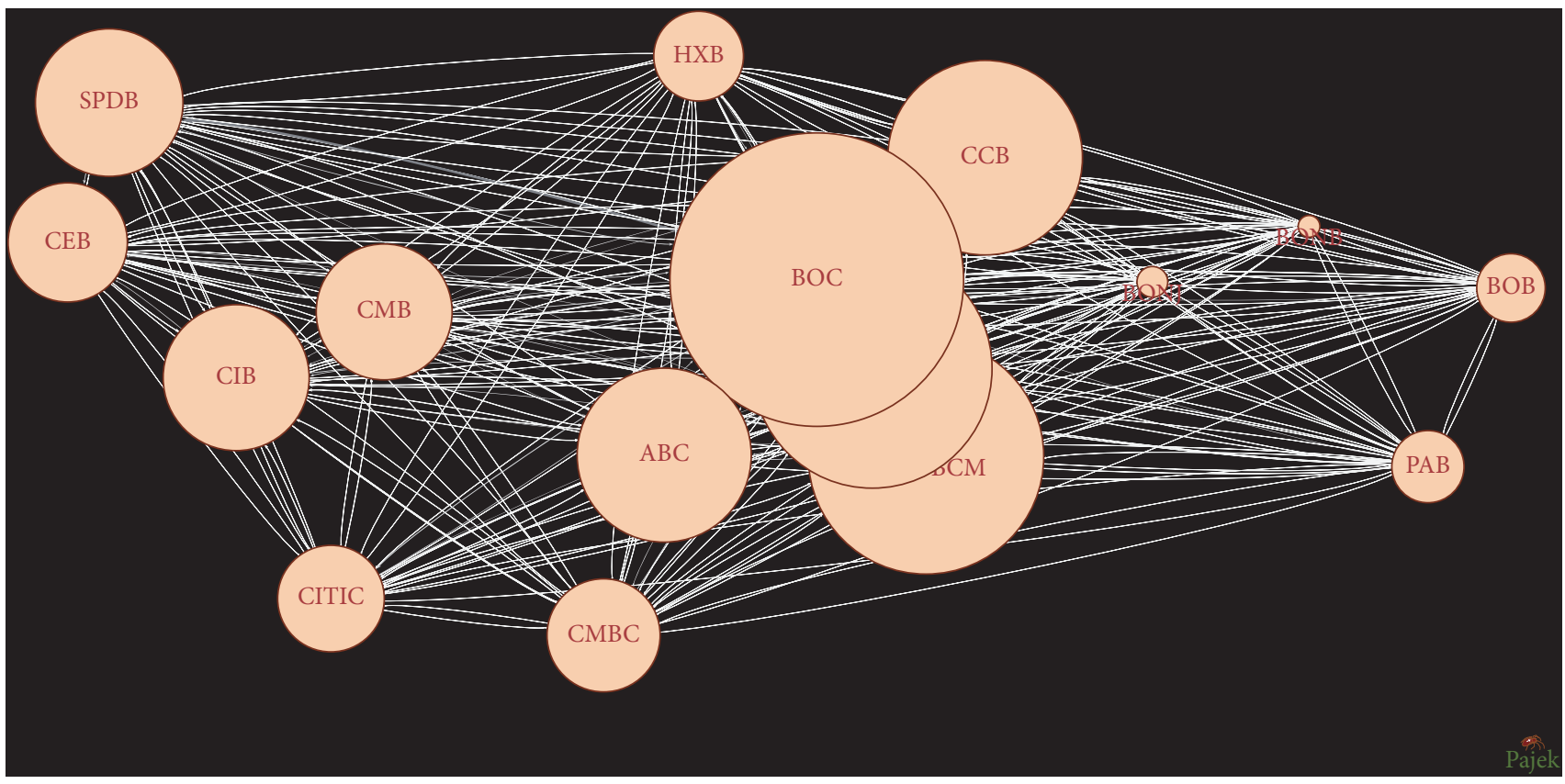

(a) 2008

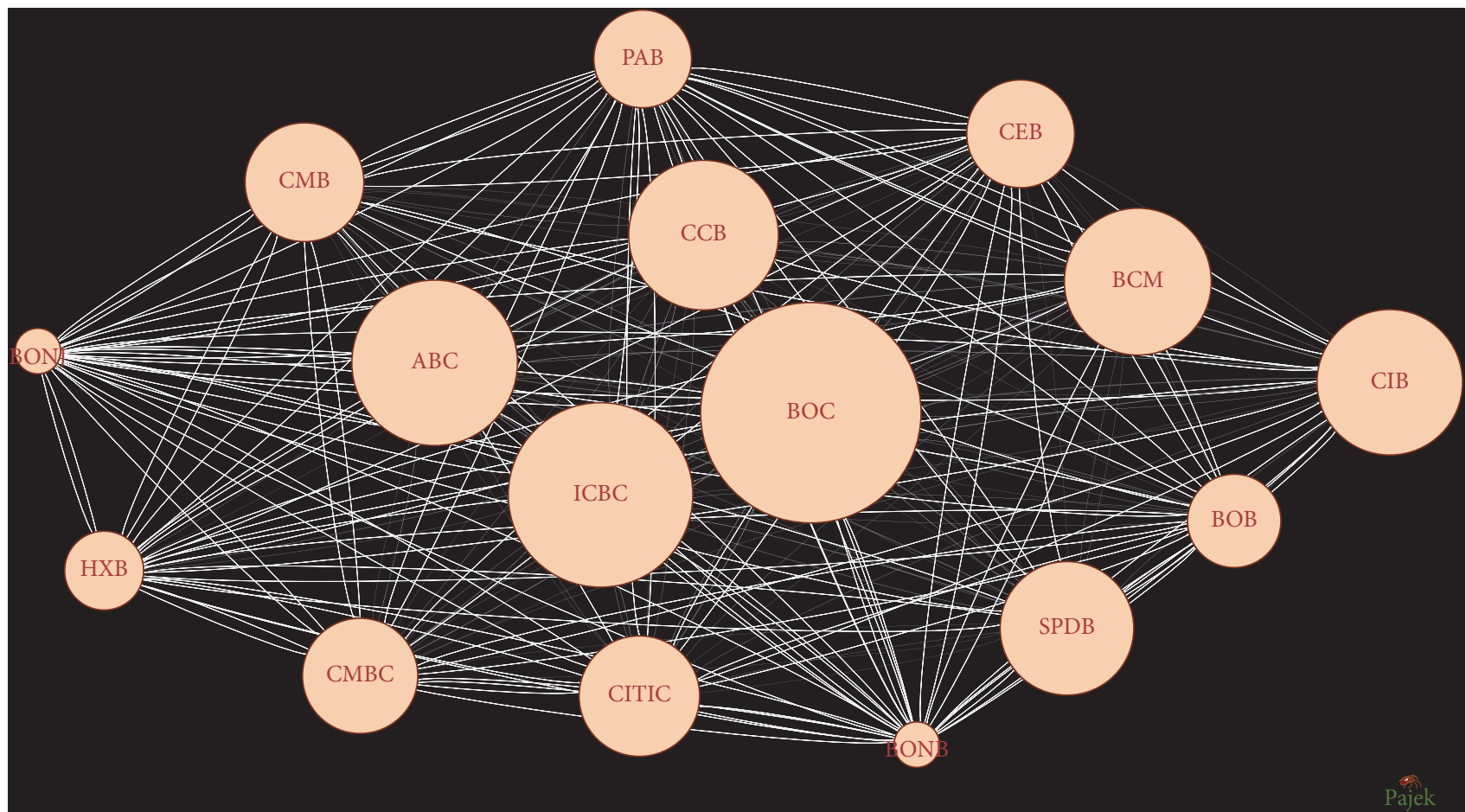

(b) 2013

FIGURE 3: A network structure diagram based on interbank borrowing and lending.

correspond to a shorter critical time. Therefore, we present the scatter-plots about the intervention on individual banks one by one to further this conclusion. It is worth mentioning that, for most banks, we cannot get a reasonable outcome and the model is not convergent due to small size of a single one, so there are only 30 banks with relative large size displayed in the scatter-plots. As shown in Figure 5, RS and $T_{\text {crit }}$ display a negative correlation both in 2008 and in 2013. It is also found that there is a sharp decline of $T_{\text {crit }}$ when the relative size is less than $2.5 \%$, which illustrates that intervention on small banks is inefficient. So in some real cases, government will give the bailouts to large individual banks such as BOC (Bank of China) or to a number of banks so that it can acquire a low $T_{\text {crit }}$ because of the large size. 


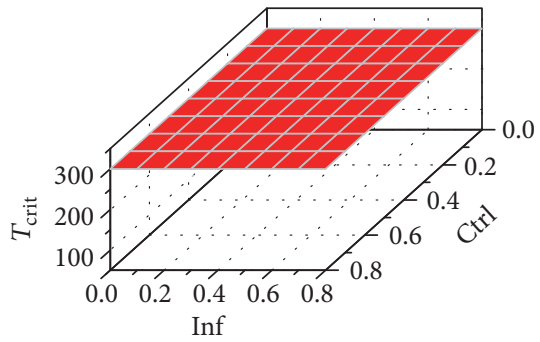

(a) 5 city commercial banks

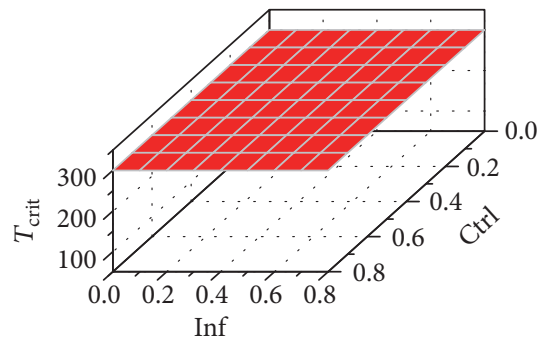

(d) 5 city commercial banks

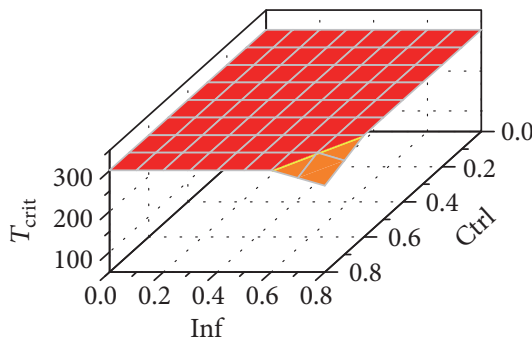

(b) 5 joint-stock banks

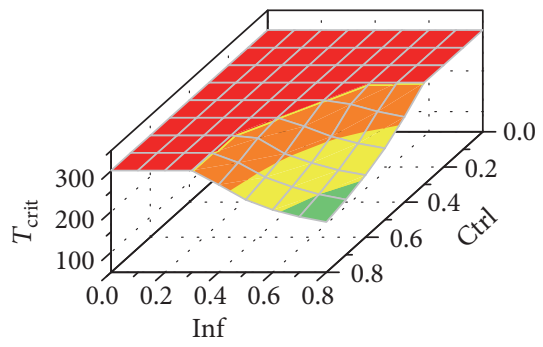

(e) 5 joint-stock banks

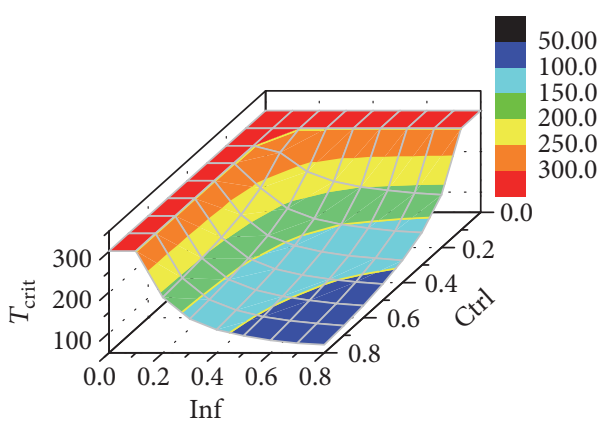

(c) 5 state-owned banks

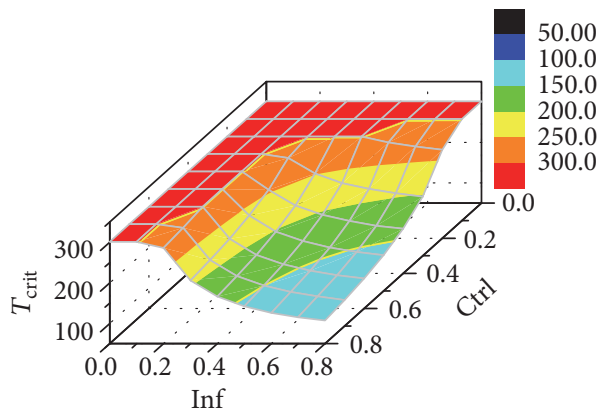

(f) 5 state-owned banks

FIGURE 4: Effects of network contagion effect (Inf) and government control strength (Ctrl) on Critical Time ( $\left.T_{\text {crit }}\right)$.
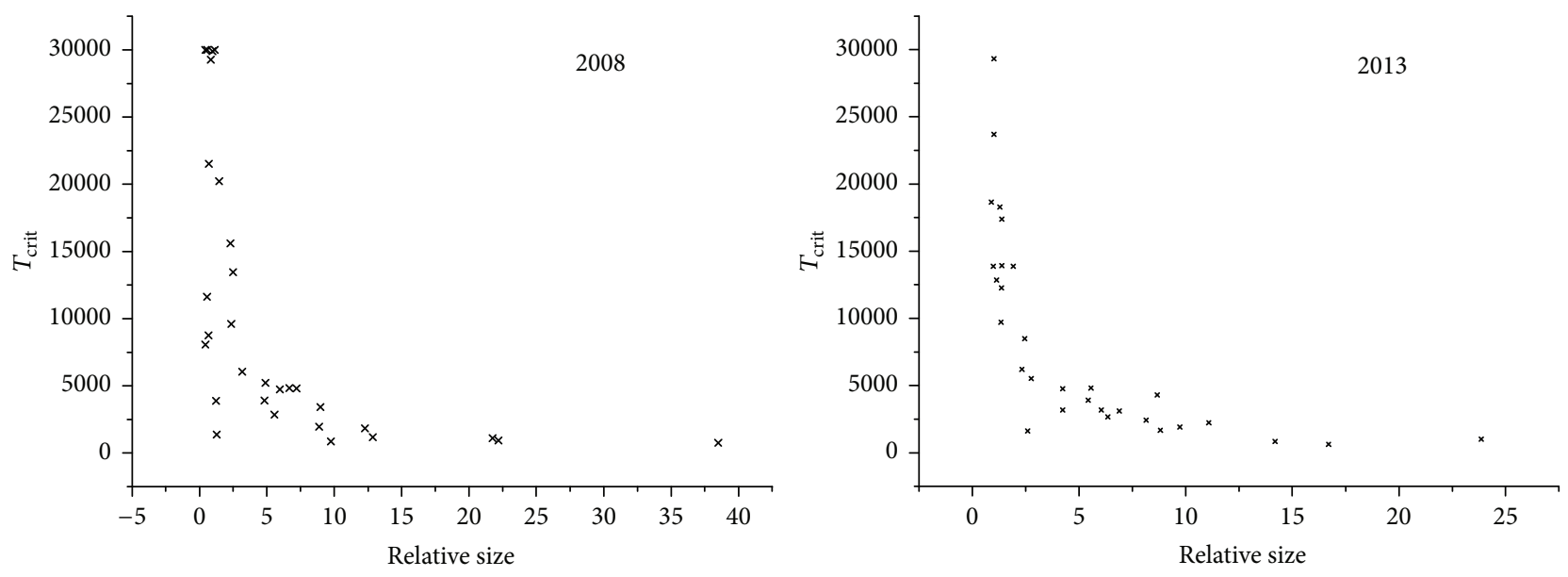

FIGURE 5: The correlation between RS and $T_{\text {crit }}$ in different years.

Furthermore, the correlation between critical time and bank size that over $2.5 \%$ is discussed below. Besides, the comparison between (b) and (e) in Figure 4 shows that the pinning control on 5 joint-stock banks had different results in 2008 and 2013, which suggests that the systemic importance of 5 joint-stock banks changed in different years. With a wide range of the stress test, the dynamic evolution model of solvency can be applied to compare the differences of bank's systemic importance in different networks.

3.3. Relative Size versus Bailout Effects. The well-known "too big to fail" theory considers that the government always gives bailouts to large banks to maintain financial stability when large banks go wrong and face bankruptcy. This paper validates the correctness of "too big to fail" theory from the perspective of pinning control and further studies the relation between bank size and bailout effects, thus enriching "too big to fail" theory based on the perspective of financial contagion.

The size of bank determines its interbank lending and borrowing size. Generally speaking, the interbank lending and borrowing size increase with the bank size, so the relative size of bank is measured by the percentage of its borrowing and lending amount in the total borrowing and lending amount of the whole bank sector. In Figure $6^{7}$, we present an 


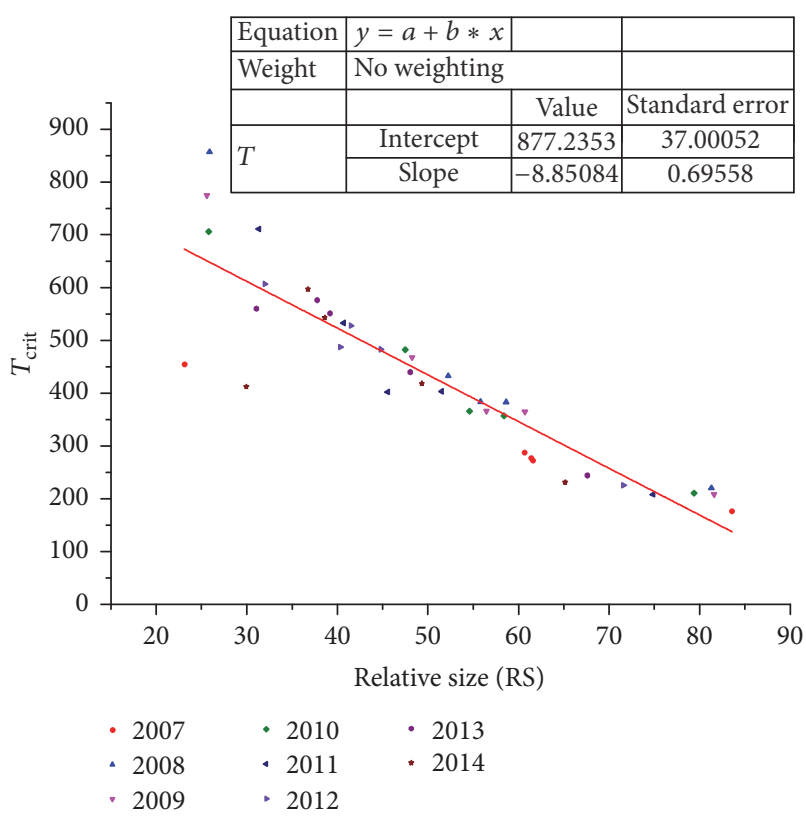

(a) $\operatorname{Inf}=0.1 ; \mathrm{Ctrl}=0.3$

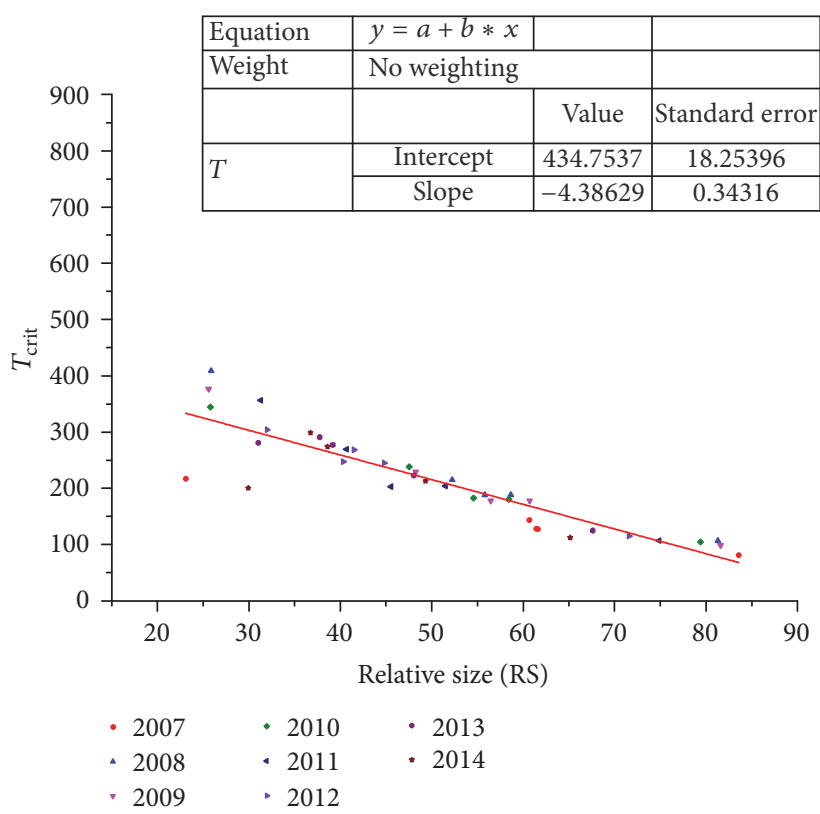

(b) $\operatorname{Inf}=0.3 ; \mathrm{Ctrl}=0.3$

FIGURE 6: The relation between relative size (RS) and systemic importance ( $\left.T_{\text {crit }}\right)$ of banks.

example for the case of Ctrl $=0.3$ and Inf $=0.1$ (panel (a)) and Inf $=0.3$ (panel (b)). The scatter diagram shows the relation between the relative size of bank receiving bailouts (RS) and the bailout effects $\left(T_{\text {crit }}\right)$.

In Figures 6(a) and 6(b), the points are color-coded by the year. It can be seen from the distribution of scattered points that RS and $T_{\text {crit }}$ show a highly negative linear correlation. The size of bank receiving bailouts determines the effects of selective bailouts to a large extent when other conditions such as the initial solvency, network contagion effect, and government control strength are same. Larger relative bank size shows a shorter critical time and a better bailout effect. It can be inferred that large banks are of greater systemic importance and this agrees with the "too big to fail" theory.

This paper further explores the relation between bank size and systemic importance when the network contagion effect changes. Through a comparison between Figures 6(a) and $6(\mathrm{~b})$, it can be found that the absolute value of linear correlation coefficient between bank size and systemic importance defined by $T_{\text {crit }}$ decreases from 8.85 to 4.39 as the network contagion effect increases from 0.1 to 0.3 , which implies the slope of fitted linear relation shrinks. Namely, critical time $\left(T_{\text {crit }}\right)$ is no longer highly elastic to relative size (RS) because of the changes of network contagion effect, which means that the changes of bank size have no significant effects on bailout results. The factors for network contagion effect such as specific social and economic contexts, fluctuations of asset prices of capital market, and the government's economic policies affect the decision-making behaviors of banks on the microscopic level and change the extent of mutual effects in the whole banking sector on the macroscopic level, so that the systemic importance is no longer sensitive to the changes of bank size. To sum up, the size of bank receiving bailouts has positive effects on its systemic importance, but the effects can be changed by the network contagion effect. To highlight this point, the larger the network contagion effect is, the smaller the elasticity of systemic importance to bank size will become.

Our conclusion is of great guiding significance for policymaking. When the contagion effect is weak in a financial system, the bailout effect is highly elastic to the bank size and the bailout effect will be obvious if the bailout is given to a large bank. Not considering the bailout cost, the optimal strategy is to give bailouts to any bank of larger size. However, when the contagion effect is strong in a financial system, the bailout effect is no longer highly sensitive to the bank size. Hence, with the bailout cost taken into consideration, it will be a better choice to give bailouts to a smaller bank within a certain range of bank size.

3.4. Spillover Effects Investigation. According to the analysis above, the dynamic evolution model of solvency based on pinning control indirectly reflects the robustness of banking sectors receiving bailouts (financial crisis first and then bailouts are given). Under different pressure and networks, various types of banks play different roles; as a result, bailouts strategies shall be decided with such factors taken into consideration. This paper is focused on the network contagion

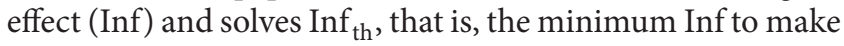
sure the critical time is not larger than a reasonable $T_{\text {crit }}$ for a given control strength $(\mathrm{Ctrl})$. How $\mathrm{Inf}_{\text {th }}$ changes with time for different types of banks is studied. Inf is actually a macroscopic indicator that measures the network contagion effect, but Inf $_{\text {th }}$ is affected by both the whole network and individual banks when $T_{\text {crit }}$ and Ctrl are given. Therefore, Inf measures the spillover effects on the whole system by different banks in different networks after receiving bailouts. The smaller $\mathrm{Inf}_{\text {th }}$ 


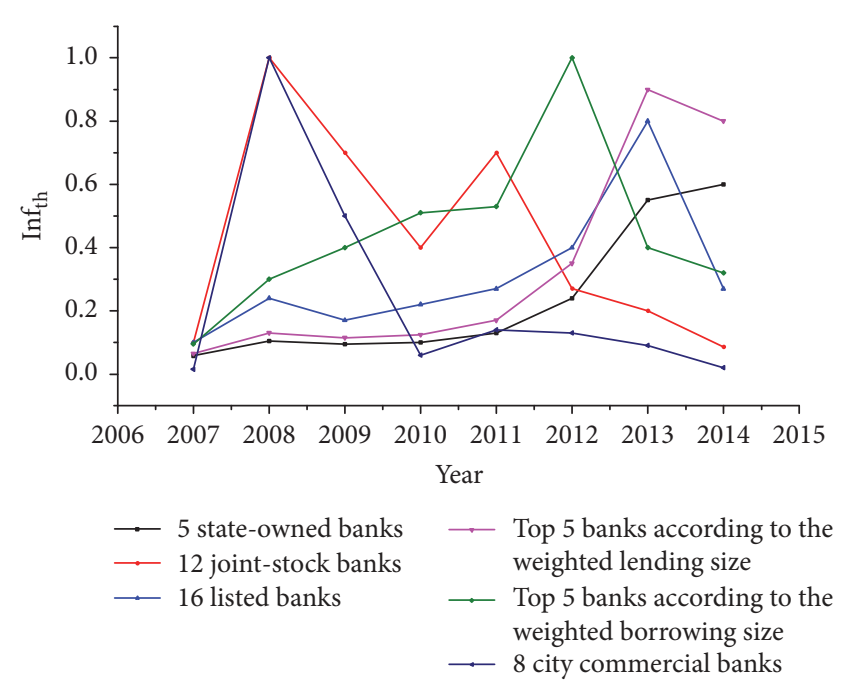

(a) The relation between $\operatorname{Inf}_{\text {th }}$ and year when Ctrl $=0.1$

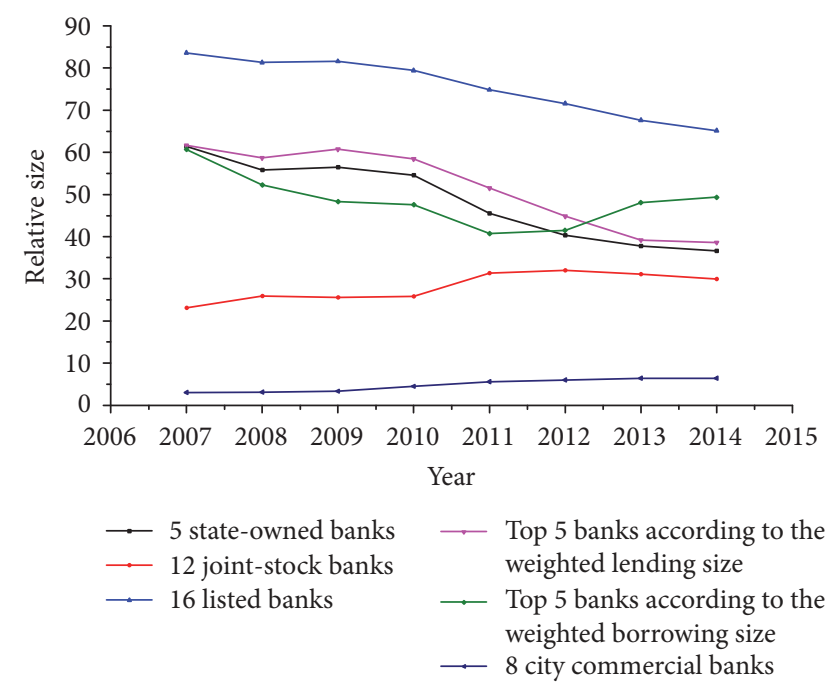

(b) The relation between year and RS

FIGURE 7: The relation between relative size (RS) and spillover effect $\left(\operatorname{Inf}_{\text {th }}\right)$ for banks receiving bailouts.

is, the smaller the minimum Inf is required to achieve same bailout effects for a certain type of banks, which implies that the government's bailouts to such a type of banks will proliferate with the help of government and vitalize the whole network; that is to say, the spillover effects are obvious. Inf $_{\text {th }}$ reflects the feedback capacity of individual banks to the macroscopic network, which is determined by individual differences and network structure jointly and thus is a kind of network effect.

Figure 7(a) shows the broken line graph of the changes of Inf $_{\text {th }}$ for different types of banks in different years when Ctrl $=0.1^{8}$. It can be seen that $\operatorname{Inf}_{\text {th }}$ of different banks varied in great ranges in 2007-2014, which suggests that the banks differed in their feedback capacity to the whole network after receiving bailouts in different years. Figure 7 (b) presents the variation curves of relative lending and borrowing size of six types of banks along with time and the fluctuations remain in a relatively stable range.

Figures $7(a)$ and $7(b)$ display a negative correlation between $\operatorname{Inf}_{\text {th }}$ and RS of different types of banks. Taking 5 state-owned banks, for example, as the relative size decreases along with time, $\operatorname{Inf}_{\text {th }}$ goes up constantly. However, it can be also observed that $\operatorname{Inf}_{\text {th }}$ of two types, namely, 12 joint-stock banks and 8 city commercial banks, fluctuated drastically in 2007-2014, though their relative sizes had no great changes. Besides, the relative size of all types of banks changed and Inf $_{\text {th }}$ decreased to different extents in 2013-2014. Therefore, the relative size is not the only decisive factor of the spillover effects for individual banks.

It can be found that $\operatorname{Inf}_{\text {th }}$ of joint-stock banks and city banks was high in 2008-2009, which suggests that two types of banks had poor proliferation after receiving bailouts and their spillover effects were insignificant. However, this was not the case for the other four types of banks. The reason could be that the global financial crisis in 2008-2009 brought about negative shocks to relatively small banks such as joint-stock banks and city banks in China's banking sector and weakened their spillover effects but large state-owned banks were slightly affected owing to the government's protection. Xu et al. [35] considered that the state offered implicit protection for listed banks but was less willing to protect city banks and joint-stock banks which were unlisted. This agrees with our research findings and explains the reason why the size of joint-stock banks is not positively correlated to their systemic importance.

Likewise, it can be found that the spillover effects of banks in 2013 were lower than those in 2014 despite the fact that their relative sizes changed differently. This could be because the "money shortage" crisis gave rise to negative shocks to China's banking sector in 2013. Above all, the dynamic evolution model of solvency is able to capture some shocks and their effects, which is of great significance for the regulatory authorities to have a better understanding of the structure of the bank system and the sensitivity and robustness of financial network to shocks.

\section{Conclusion and Discussions}

In this paper, the financial network is constructed based on interbank borrowing and lending; furthermore, a dynamic evolution model of solvency is developed. With the financial crisis arising from given exogenous shocks, the effects of different bailouts are studied by pinning control theory.

Firstly, stress test is applied in China's interbank lending and borrowing network based on the dynamic evolution model of solvency and the results are as follows. The size of bank is a crucial to its systemic importance, but the network contagion effect can significantly change the elasticity of systemic importance with respect to bank size. Therefore, when it comes to a financial network with small contagion, the optimal strategy for the government is to give bailouts to large banks because the bailout effects are highly elastic to 
bank size; on the contrary, for a financial network with large contagion effects, it will be a better decision to give bailouts to small banks because the bailout effects are slightly elastic to bank size and the bailouts to large banks may suffer from an enormous cost.

An investigation on different types of banks in different years is conducted and it is found that the size of bank is positively correlated to its spillover effects under normal circumstances, but exogenous shocks such as the global financial crisis in 2008 and the "money shortage" crisis in 2013 significantly affected the spillover effects of banks in different extents. Besides, the spillover effects are also sensitive to government control strength and network contagion effect. But the impact of former is more remarkable, which reveals that it would be obviously efficient for policymakers to improve the control strength.

This paper offers a new tool for stress test to analyze the macroscopic system with the network perspective, which is able to reveal the sensitivity of bank system to policies in different economic contexts, capture the effects of exogenous shocks, and identify the systemic-important banks based on their spillover effects. This completely agrees with the macroprudential regulation and has been seldom discussed in some research with traditional tools and analytical methods. Therefore, the dynamic evolution model of solvency for stress test proposed on the basis of pinning control is very significant extremely for the regulation authorities in establishing macroprudential regulation framework and methods.

\section{Notations}

Main Parameters for the Dynamic Evolution Model of Solvency

Solvency $_{i}(t)$ : The solvency of bank $i$ at time $t$

$X_{i j}$ : The percentage of the lending amount of bank $i$ to bank $j$ in the total lending amount of bank $i$ (interrelation degree)

Inf: The extent to which the solvency of a bank is affected by that of interrelated banks in a given network (contagion)

Ctrl: The control strength of the government's bailouts in a given network

SC: $\quad$ Contraction of supply due to default risk

Aim: $\quad$ The desired values for the system

$T_{\text {crit }}$ : The time it takes for all banks in the system to reach the desired values (critical time)

Inf $_{\text {th }}$ : The minimum Inf for given Ctrl and $T_{\text {crit }}$

$\operatorname{Ctrl}_{\text {th }}$ : The minimum Ctrl for given Inf and $T_{\text {crit }}$.

\section{Conflicts of Interest}

The authors declare that there are no conflicts of interest regarding the publication of this paper.

\section{Acknowledgments}

This project was supported by Chinese Fundamental Research Funds for the Central Universities (HUST: 2015AD006).

\section{Endnotes}

1. A wealth of relevant literature has reported the application of a directed network composed of weighted edges and nodes showing one-to-one correspondence with banks for the purpose of network estimation and thus the mechanism is not explained here. In addition, some literature has highlighted the fact that the maximum entropy method is unable to reflect the actual conditions faithfully because of its inherent defects (e.g., the assumption of complete market structure and the underestimation of risk contagion effect). However, in this paper, it is used to reflect the relative interrelation degree among banks through interbank lending and borrowing and its defects have no significant effects on the subsequent research findings.

2. In this paper, the repeated experiments are conducted when the initial values of solvency are taken from the ranges of $[0.1,0.3],[0.3,0.5],[0.4,0.6]$, and $[0.5,0.7]$. As the initial conditions are consistent in different contexts, the conclusions agree with what is drawn in the main body of this paper, which implies that the range of initial solvency has no significant effects on the research results. In addition, to avoid the interference from random assignment, ten experiments are conducted for the random assignment of initial solvency in each network and the results remain highly consistent.

3. Since both Ctrl and Inf are influential to judgment indicators, one should remain changeless to study the other.

4. Since the matrix elements are relative values and the banks of undisclosed data account for a small proportion in the banking sector, the different numbers of banks in different years have no effects on subsequent analysis.

5. Abbreviations in Figure 3, respectively, refer to BCM (Bank of Communications); CMBC (China Minsheng Banking Co., Ltd); ICBC (Industrial and Commercial Bank of China); CCB (China Construction Bank); PAB (Ping An Bank); BOC (Bank of China); BONJ (Bank of Nanjing); CMB (China Merchants Bank Ltd); CITIC (China CITIC Bank); CEB (China Everbright Bank); CIB (Industrial Bank Co,. Ltd); HXB (Huaxia Bank); SPDB (Shanghai Pudong Development Bank); BOB (Bank of Beijing); BONB (Bank of Ningbo); ABC (Agricultural Bank of China).

6. Three types of banks under pinning control include the following: 5 city commercial banks are Bank of Beijing, Bank of Shanghai, Bank of Nanjing, Bank of Jiangsu, and Bank of Ningbo; 5 joint-stock banks are China CITIC Bank, China Minsheng Bank Co., Ltd, China Merchants Bank, Industrial Bank Co., Ltd., and SPD Bank; 5 state-owned banks are Industrial and Commercial Bank of China, Agricultural Bank of China, Bank of China, China Construction Bank, and Bank of Communications. Since the critical time for three types of banks differs greatly, $T \leq 300$ is intercepted to better reflect the changes of three parameters. 
7. The weighted borrowing size means the percentage of borrowing amount in total borrowing amount and top 5 banks are selected according to their weighted borrowing size; the weighted lending size means the percentage of lending amount in total lending amount and top 5 banks are selected according to the weighted lending size.

8. To better reflect the changes, $T_{\text {crit }}$ varies for six types of banks, that is, $T_{\text {crit }}=550$ for 5 state-owned banks, $T_{\text {crit }}=650$ for 12 joint-stock banks, $T_{\text {crit }}=250$ for 16 listed banks, $T_{\text {crit }}=500$ for top 5 banks in the weighted borrowing size, $T_{\text {crit }}=500$ for top 5 banks in the weighted lending size, and $T_{\text {crit }}=4500$ for 8 city commercial banks; a horizontal comparison of $T_{\text {crit }}$ in the same year is meaningless, so its time-varying trends for different types of banks are compared. In addition, 8 city commercial banks include Bank of Beijing, Bank of Shanghai, Bank of Nanjing, Bank of Jiangsu, Bank of Tianjin, Bank of Ningbo, Shengjing Bank, and Bank of Hangzhou.

\section{References}

[1] B. Rost, Basel Committee on Banking Supervision, Cambridge University Press, Cambridge, UK, 2009.

[2] F. Allen and D. Gale, "Financial contagion," Journal of Political Economy, vol. 108, no. 1, pp. 1-33, 2000.

[3] K. Anand, P. Gai, and M. Marsili, "Rollover risk, network structure and systemic financial crises," Journal of Economic Dynamics \& Control, vol. 36, no. 8, pp. 1088-1100, 2012.

[4] N. Paltalidis, D. Gounopoulos, R. Kizys, and Y. Koutelidakis, "Transmission channels of systemic risk and contagion in the European financial network," SSRN Electronic Journal, vol. 61, no. 1, pp. 36-52, 2015.

[5] O. Castrén and M. Rancan, "Macro-Networks: an application to euro area financial accounts," Journal of Banking \& Finance, vol. 46, no. 1, pp. 43-58, 2014.

[6] L. Eisenberg and T. H. Noe, "Systemic risk in financial systems," Management Science, vol. 47, no. 2, pp. 236-249, 2001.

[7] N. Kiyotaki and J. Moorek, "Credit cycles," Journal of Political Economy, vol. 106, pp. 211-248, 1997.

[8] Co-Pierre, "The effect of the interbank network structure on contagion and common shocks," Journal of Banking \& Finance, vol. 37, no. 7, pp. 2216-2228, 2013.

[9] S. Battiston, M. Puliga, R. Kaushik, P. Tasca, and G. Caldarelli, "DebtRank: too central to fail? financial networks, the FED and systemic risk," Scientific Reports, vol. 2, article no. 541, 2012.

[10] C. Huang and Y. Jia, "Macroprudential regulation from the perspective of financial network: empirical analysis based on interbank payment and settlement data," Journal of Financial Research, vol. 4, pp. 1-14, 2010.

[11] A. Sokolov, R. Webster, A. Melatos, and T. Kieu, "Loan and nonloan flows in the Australian interbank network," Physica A: Statistical Mechanics and its Applications, vol. 391, no. 9, pp. 2867-2882, 2012.

[12] M. Drehmann and N. Tarashev, "Measuring the systemic importance of interconnected banks," Journal of Financial Intermediation, vol. 22, no. 4, pp. 586-607, 2013.

[13] P. E. Mistrulli, "Assessing financial contagion in the interbank market: maximum entropy versus observed interbank lending patterns," SSRN Electronic Journal, vol. 35, no. 5, pp. 1114-1127, 2011.

[14] H. A. Degryse and G. Nguyen, "Interbank exposure: an empirical examination of systemic risk in the belgian banking system," International Journal of Central Banking, vol. 3, pp. 123-172, 2007.

[15] J. Ma, X. Fan, and Y. Cao, "Estimation of bilateral contagion risks and analysis of systemic characteristics for china's interbank market," Economic Research Journal, vol. 1, pp. 68-78, 2007.

[16] M. Wang, J. He, and S. Li, "A study on risk measurement of bank system based on borrowing and lending preference," Chinese Journal of Management Science, vol. s1, pp. 237-243, 2013.

[17] K. Anand, B. Craig, and G. V. Peter, "Filling in the blanks: network structure and interbank contagion," Quantitative Finance, vol. 15, no. 4, pp. 625-636, 2015.

[18] H. Ouyang and X. Liu, "A study on systemic importance of financial institutions based on network analysis," Management World, vol. 8, pp. 171-172, 2014.

[19] X. Fan, D. Wang, and L. Liu, "Bank size, interrelation and measurement of China's systemic important banks," Journal of Financial Research, vol. 11, pp. 16-30, 2012.

[20] S. Ba, W. Zuo, and Y. Q. Zhu, "Effects of financial network and contagion on financial stability, research on financial and economic issues," Research on Financial and Economic Issues, vol. 2, pp. 3-11, 2013.

[21] K. Soramäki, M. L. Bech, J. Arnold, R. J. Glass, and W. E. Beyeler, "The topology of interbank payment flows," Physica A: Statistical Mechanics and its Applications, vol. 379, no. 1, pp. 317333, 2007.

[22] M. L. Bech and E. Atalay, "The topology of the federal funds market," Physica A: Statistical Mechanics and its Applications, vol. 389, no. 22, pp. 5223-5246, 2010.

[23] M. Boss, H. Elsinger, M. Summer, and S. Thurner, "Network topology of the interbank market," Quantitative Finance, vol. 4, no. 6, pp. 677-684, 2004.

[24] X. Li, X. Wang, and G. Chen, "Pinning a complex dynamical network to its equilibrium," IEEE Transactions on Circuits and Systems I: Regular Papers, vol. 51, no. 10, pp. 2074-2087, 2004.

[25] X. F. Wang and G. Chen, "Pinning control of scale-free dynamical networks," Physica A: Statistical Mechanics and its Applications, vol. 310, no. 3-4, pp. 521-531, 2002.

[26] M. Afshar and M. Asadpour, "Opinion formation by informed agents," Journal of Artificial Societies \& Social Simulation, vol. 13, pp. 451-453, 2010.

[27] H. Gang and Q. Zhilin, "Controlling spatiotemporal chaos in coupled map lattice systems," Physical Review Letters, vol. 72, no. 1, pp. 68-71, 1994.

[28] X. Wang and H. Su, "Pinning control of complex networked systems: a decade after and beyond," Annual Reviews in Control, vol. 38, no. 1, pp. 103-111, 2014.

[29] Z. H. Rong, X. Li, and W. L. Lu, "Pinning a complex network through the betweenness centrality strategy," in Proceedings of the 2009 IEEE International Symposium on Circuits and Systems, (ISCAS '09), pp. 1689-1692, IEEE, Taipei, Taiwan, May 2009.

[30] W. K. S. Tang, K.-H. Ng, and Q. Jia, "A degree-based strategy for constrained pinning control of complex networks," International Journal of Bifurcation and Chaos, vol. 20, no. 5, pp. 15331539, 2010.

[31] L. F. R. Turci and E. E. N. Macau, "Performance of pinningcontrolled synchronization," Physical Review E: Statistical, Nonlinear, and Soft Matter Physics, vol. 84, no. 1, Article ID 011120, 2011. 
[32] Y. Zou and G. Chen, "Choosing effective controlled nodes for scale-free network synchronization," Physica A: Statistical Mechanics and its Applications, vol. 388, no. 14, pp. 2931-2940, 2009.

[33] S. Levy-Carciente, D. Y. Kenett, A. Avakian, H. E. Stanley, and S. Havlin, "Dynamical macroprudential stress testing using network theory," Journal of Banking \& Finance, vol. 59, pp. 164181, 2015.

[34] C. Upper and A. Worms, "Estimating bilateral exposures in the German interbank market: is there a danger of contagion?" European Economic Review, vol. 48, no. 4, pp. 827-849, 2004.

[35] Y. Xu, Q. Liu, and K. Chen, "Probability and cost of Chinese governments implicit bailouts for listed banks," Journal of Financial Research, vol. 10, pp. 60-74, 2012. 


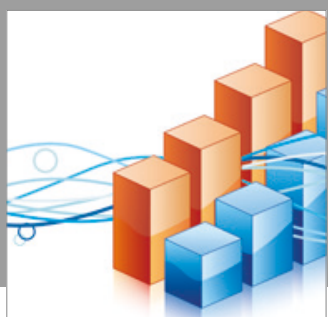

Advances in

Operations Research

vatersals

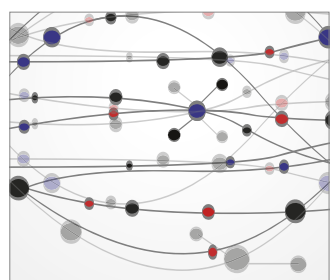

\section{The Scientific} World Journal
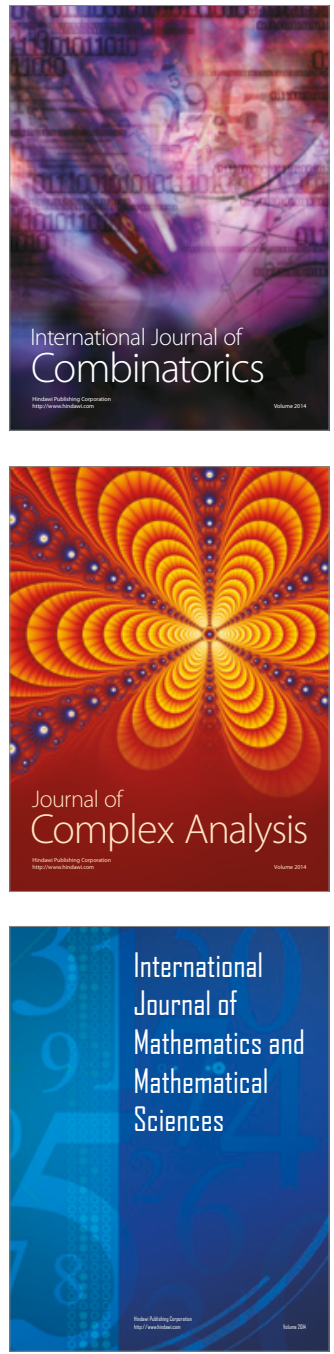
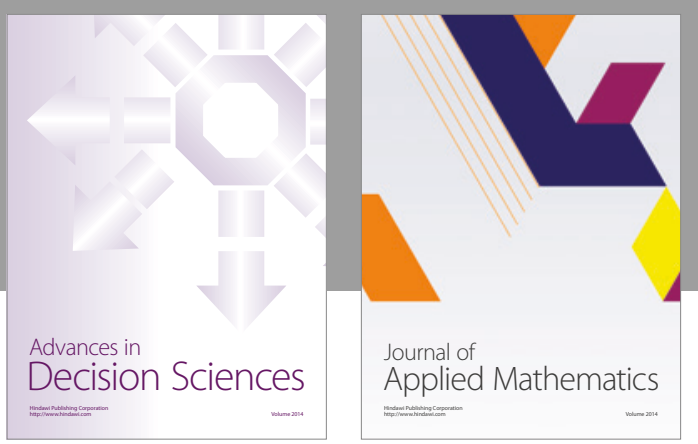

Algebra

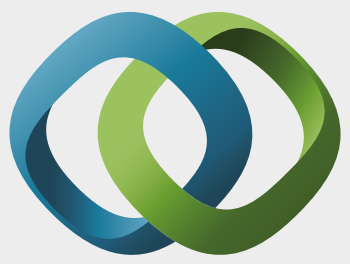

\section{Hindawi}

Submit your manuscripts at

https://www.hindawi.com
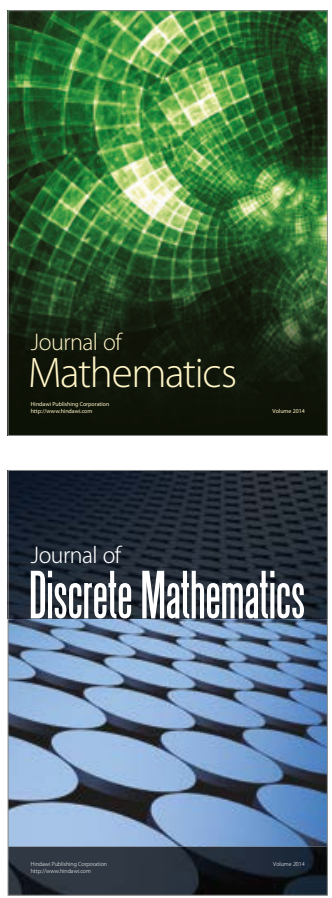

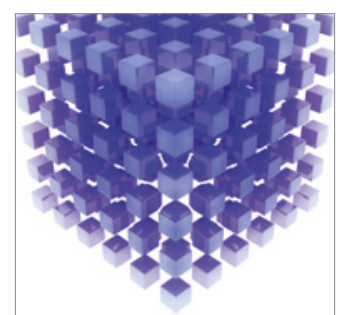

Mathematical Problems in Engineering
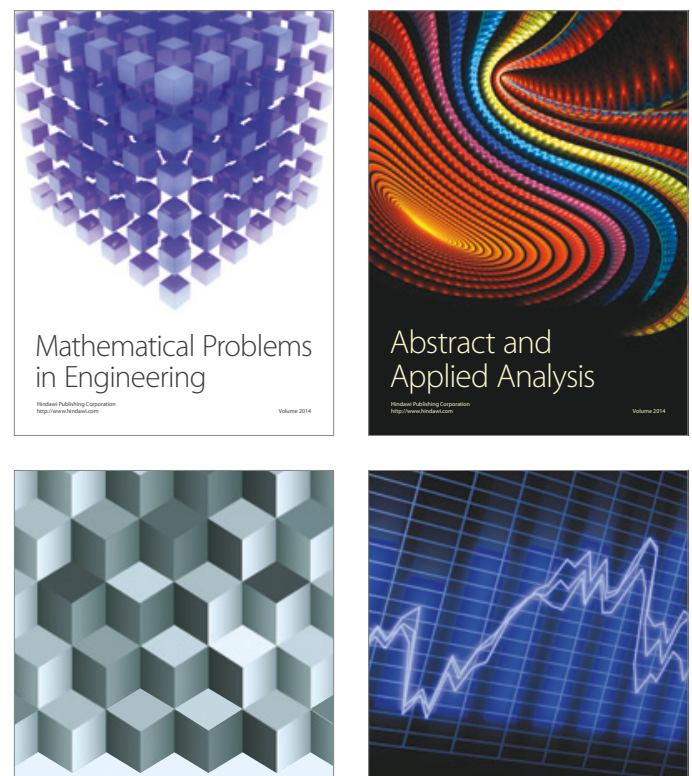

Journal of

Function Spaces

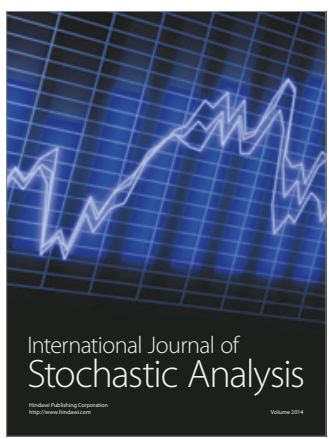

Probability and Statistics
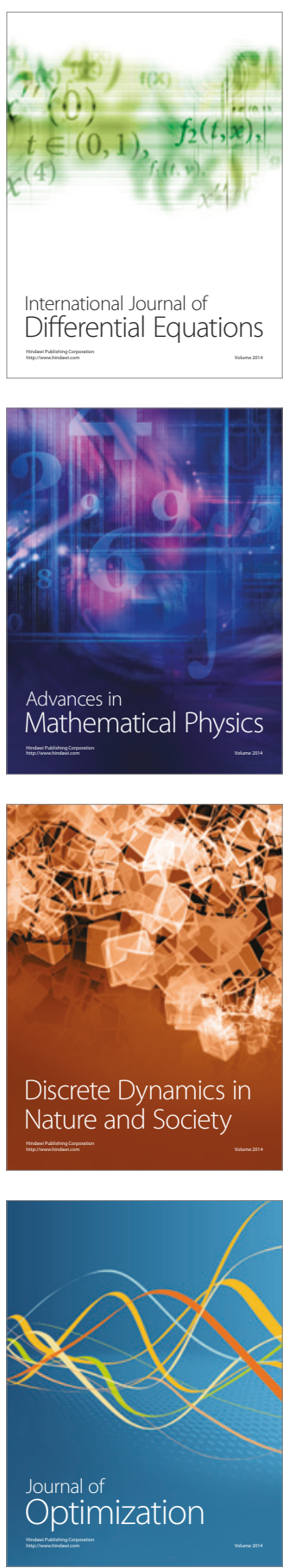